\title{
Reporting of Adverse Drug Reactions in Primary Care Settings in Kuwait: A Comparative Study of Physicians and Pharmacists
}

\author{
Jacinthe Lemay ${ }^{a} \quad$ Fatemah M. Alsaleh ${ }^{b} \quad$ Lulwa Al-Bureslia \\ Mohammed Al-Mutairi $^{a}$ Eman A. Abahussain ${ }^{b}$ Tania Bayoud ${ }^{b}$ \\ ${ }^{a}$ Department of Pharmacology and Therapeutics, Faculty of Pharmacy, Kuwait University, Kuwait City, Kuwait; \\ ${ }^{b}$ Department of Pharmacy Practice, Faculty of Pharmacy, Kuwait University, Kuwait City, Kuwait
}

\section{Significance of the Study}

- In this study, pharmacists showed a better knowledge than physicians of pharmacovigilance and adverse drug reactions (ADR) in the primary care setting. Despite positive attitudes, ADR reporting practices were suboptimal, and the major barriers identified were not knowing how to report information and what information to report. These findings could help tailor interventions to increase reporting in collaboration with the Kuwait Drug and Food Control.

\section{Keywords}

Pharmacovigilance $\cdot$ Adverse drug reaction · Primary care

\begin{abstract}
Objective: To investigate and compare knowledge, attitudes, and practices regarding pharmacovigilance (PV) and the reporting of adverse drug reactions (ADR) among physicians and pharmacists in primary care settings. Subjects and Methods: A cross-sectional study was conducted, in which a validated self-administered questionnaire was distributed to 386 physicians and 197 pharmacists in 38 primary care clinics in Kuwait. Categorical variables were described using numbers and percentages. The Pearson $x^{2}$ test, Fisher exact test, and Mann-Whitney $U$ test were used as appropriate. $p<0.05$ was considered statistically significant. Results: Of the 583 questionnaires distributed, 485 were completed (by 318 physicians and 167 pharmacists), giving an overall response
\end{abstract}

\begin{tabular}{ll}
\hline KARGER & (c) 2018 The Author(s) \\
Published by S. Karger AG, Basel & Karger \\
E-Mail karger@karger.com & $\begin{array}{l}\text { This is an Open Access article licensed under the Creative Commons } \\
\text { Attribution-NonCommercial-4.0 International License (CC BY-NC) } \\
\text { (http://www.karger.com/Services/OpenAccessLicense), applicable to } \\
\text { the online version of the article only. Usage and distribution for } \\
\text { commercial purposes requires written permission. }\end{array}$
\end{tabular}

rate of $83.2 \%$. A total of $52.8 \%(n=256)$ and $70.5 \%(n=341)$ of the study participants were knowledgeable about the definitions of PV and ADR, respectively, with pharmacists demonstrating significantly better knowledge of PV $(n=105 / 167$ vs. $151 / 318$, i.e., 62.9 vs. $47.5 \% ; p<0.001)$ and purpose $(n=$ $123 / 167$ vs. $177 / 318$, i.e., 74.1 vs. $55.7 \%$; $p<0.001$ ). However, the majority ( $n=434 / 485 ; 89.4 \%$ ) were not aware of an ADR reporting system in Kuwait. Almost every participant ( $n=$ 474/485; 97.7\%) thought it was necessary to report ADR. However, significantly fewer physicians than pharmacists ( $n=248 / 318$ vs. $147 / 167$, i.e., 78.0 vs. $88.0 \%$; $p<0.01$ ) believed that ADR reporting was a professional obligation. Only $27.8 \%$ ( $n=133 / 485$ ) had reported ADR, with pharmacists having reported significantly fewer than physicians ( $n=$ $35 / 167$ vs. $98 / 318$, i.e., 21.7 vs. $30.8 \% ; p=0.036$ ). Conclusions: This study indicated that the attitude was positive but there was suboptimal knowledge and poor practice among primary care physicians and pharmacists with regard to ADR re- 
porting. Targeted training about ADR reporting while ensuring a robust regulatory framework would encourage ADR reporting practices in the primary health care setting in Kuwait.

(C) 2018 The Author(s)

Published by S. Karger AG, Basel

\section{Introduction}

Primary health care professionals (HCP) represent the first contact point within the health care system when a patient encounters a health problem. As such, they form an essential part of the health care system. They contribute to reducing morbidity, emergency room visits, and hospitalizations [1]. With a population of approximately 4.2 million, the State of Kuwait offers private and public health care systems. The latter is composed of 94 primary care and 6 secondary care polyclinics and 9 specialized tertiary care hospitals. Data from the primary health care setting in 2013 showed that there were 19.9 million patient visits, with an average of about 52,000 visits daily [2]. The Ministry of Health $(\mathrm{MoH})$ in Kuwait is striving to obtain accreditation of public health care institutions, including polyclinics, from Accreditation Canada International [3]. The Canadian standards focus on the essential components of a safe health care system. Several standards state that a crucial function of any service is adverse drug reaction (ADR) identification, management, and reporting that should be supported by clear guidelines, policies, and procedures [3].

Data from a systematic review showed that ADR were associated with up to $15 \%$ of hospital admissions and prolonged hospitalizations, and are considered as the fourth leading cause of mortality in the USA [4]. ADR reporting is a pivotal part of a reliable pharmacovigilance (PV) system. National PV centers have played a significant role in increasing public awareness of the issues relevant to the safety of medicines [5]. Several countries in the Middle East lack a functional and coordinated national PV program [6]. Some of these countries have collaborated to develop a guideline on good pharmacovigilance practices for Arab countries to implement harmonized PV practices in the region [7]. Kuwait Drug and Food Control (KDFC) has implemented several PV initiatives, such as guidelines for marketing authorization holders and online ADR reporting, but it has yet to have a formal PV unit.

ADR are underreported and unrecognized by HCP $[8$, 9]. In Kuwait, a recent study of hospital pharmacists showed similar results: adequate knowledge, positive attitudes, and poor ADR reporting practices [10]. Similar findings were observed among community pharmacists in neighboring countries $[11,12]$. It remains to be determined whether or not similar findings would be observed among HCP in primary care. Data from the Middle East region show that, although knowledge regarding PV and $\mathrm{ADR}$ reporting is adequate and the attitude is positive regarding the implementation of reporting in daily practice, ADR reporting remains poor [13]. Data from hospital settings in Saudi Arabia showed that most HCP were aware of the need to report ADR but were not aware of a reporting system at their institution, so very few were reporting ADR [14]. Given the importance of primary health care services in Kuwait, the volume of patients seen daily and the MoH's objective of obtaining accreditation for its public institutions, it is imperative to determine if there are gaps in the knowledge, attitudes, and practices of this primary health care setting in order to develop strategies that will address such gaps. Furthermore, since physicians and pharmacists are the two main HCP involved in the delivery of health care in the primary care setting, it is important to assess their knowledge, attitude, and practices as well as any barriers to ADR reporting, with the ultimate objective of subsequently developing a tailored approach that will improve reporting practices. The objective of this study was to investigate and compare the knowledge, attitudes, and practices regarding PV and $\mathrm{ADR}$ reporting among physicians and pharmacists in primary care settings.

\section{Subjects and Methods}

Study Design, Population, and Tools

A descriptive, cross-sectional study was carried out from January to May 2016 among physicians and pharmacists across 38 primary care polyclinics within the 5 health governorates of Kuwait. All physicians and pharmacists who work in the polyclinics were considered eligible. The Standing Committee for the Coordination of Health and Medical Research, the MoH, and the Health Sciences Center Ethics Committee for Student Research approved this study.

The study tool was a self-administered questionnaire based on previous local and international studies that examined the knowledge, attitudes, and practices of HCP $[10,11,15,16]$. It consisted of 26 questions structured in 5 different sections to assess knowledge, attitudes, practices, and barriers to PV and ADR reporting, and was distributed in English, given that participants were conversant with the English language. The WHO definitions of ADR and PV were used [7]. The questionnaire consisted of items from self-administered pretested questionnaires used in previously published studies $[10,11,15-18]$. The questionnaire items were revised and validated by 2 researchers with expertise in the field, concerning relevance, clarity, and reflection of the research hypothesis. To ensure the feasibility of the data collection methods, 
Table 1. Sociodemographic characteristics of 485 participants

\begin{tabular}{|c|c|c|c|c|}
\hline & $\begin{array}{l}\text { Physicians, } \\
n=318(65.6 \%)\end{array}$ & $\begin{array}{l}\text { Pharmacists, } \\
n=167(34.4 \%)\end{array}$ & $\begin{array}{l}\text { Total, } \\
n=485(100 \%)\end{array}$ & $p$ value \\
\hline Gender & & & & $0.064^{\mathrm{a}}$ \\
\hline Female & $188(59.1)$ & $83(50.3)$ & $271(56.1)$ & \\
\hline Age & & & & $<0.001^{\mathrm{a}}$ \\
\hline $20-29$ years & $16(5.0)$ & $27(16.2)$ & $43(8.9)$ & \\
\hline$\geq 50$ years & $86(27.0)$ & $25(15.0)$ & $111(22.9)$ & \\
\hline Mean age $\pm S D$, years & $41.7 \pm 9.8$ & $36.7 \pm 8.6$ & $40.0 \pm 9.7$ & $<0.001^{\mathrm{b}}$ \\
\hline Years of experience & & & & $<0.001^{\mathrm{a}}$ \\
\hline $1-5$ & $31(9.7)$ & $41(24.6)$ & $72(14.8)$ & \\
\hline $6-10$ & $73(23.0)$ & $39(23.4)$ & $112(23.1)$ & \\
\hline Kuwaiti & $66(21.2)$ & $58(35.6)$ & $124(26.2)$ & \\
\hline Non-Kuwaiti ${ }^{1}$ & $245(78.8)$ & $105(64.4)$ & $350(73.8)$ & \\
\hline Country of graduation & & & & $0.125^{\mathrm{a}}$ \\
\hline Kuwait & $49(15.4)$ & $35(21.0)$ & $84(17.3)$ & \\
\hline Outside Kuwait $^{2}$ & $269(84.6)$ & $132(79.0)$ & $401(82.7)$ & \\
\hline
\end{tabular}

Values are expressed as $n(\%)$, unless otherwise indicated; they may not add up due to missing data. $p$ values were generated using the: ${ }^{\mathrm{a}}$ Pearson $\chi^{2}$ test, ${ }^{\mathrm{b}}$ independent $t$ test, and ${ }^{\mathrm{c}}$ Mann-Whitney U test.

${ }^{1}$ Egypt $(n=249)$, Syria $(n=41)$, India $(n=15)$, Pakistan $(n=14)$ Palestine $(n=7)$, Others $(n=24)$.

${ }^{2}$ Egypt $(n=266)$, Kuwait $(n=84)$, Syria $(n=39)$, Jordan $(n=18)$, Pakistan $(n=16)$, India $(n=13)$, Bahrain $(n=12)$, UK $(n=6)$, United Arab Emirates $(n=5)$, Others $(n=16)$.

Table 2. Knowledge of PV and ADR among physicians and pharmacists working in polyclinics in Kuwait $(n=485)$

\begin{tabular}{|c|c|c|c|c|}
\hline & $\begin{array}{l}\text { Physicians, } \\
n=318(65.6 \%)\end{array}$ & $\begin{array}{l}\text { Pharmacists, } \\
n=167(34.4 \%)\end{array}$ & $\begin{array}{l}\text { Total, } \\
n=485(100 \%)\end{array}$ & $p$ value \\
\hline Definition of PV & $151(47.5)$ & $105(62.9)$ & $256(52.8)$ & $<0.001^{\mathrm{a}}$ \\
\hline Purpose of PV & $177(55.7)$ & $123(74.1)$ & $300(62.0)$ & $<0.001^{\mathrm{a}}$ \\
\hline Definition of ADR & $212(66.7)$ & $129(77.7)$ & $341(70.5)$ & $0.146^{\mathrm{b}}$ \\
\hline Knowing which ADR should be reported & $254(79.9)$ & $110(66.3)$ & $364(75.2)$ & $0.001^{\mathrm{b}}$ \\
\hline Aware of an ADR reporting system in Kuwait & $28(8.8)$ & $23(14.3)$ & $51(10.6)$ & $0.066^{\mathrm{a}}$ \\
\hline \multicolumn{5}{|l|}{ To whom should ADR be reported in Kuwait? ${ }^{1}$} \\
\hline KDFC & $84(26.4)$ & $69(41.3)$ & $153(31.5)$ & $0.001^{\mathrm{a}}$ \\
\hline $\mathrm{MoH}$ & $108(34.0)$ & $70(41.9)$ & $178(36.7)$ & $0.084^{\mathrm{a}}$ \\
\hline Drug manufacturers & $48(15.1)$ & $40(24.0)$ & $88(18.1)$ & $0.016^{\mathrm{a}}$ \\
\hline Working hospitals/clinics & $104(32.7)$ & $42(25.1)$ & $146(30.1)$ & $0.085^{\mathrm{a}}$ \\
\hline I don't know & $128(40.3)$ & $45(26.9)$ & $173(35.7)$ & $0.004^{\mathrm{a}}$ \\
\hline
\end{tabular}

Values are expressed as $n(\%)$ and may not add up due to missing data. ADR, adverse drug reactions; KDFC, Kuwait Drug and Food Control; $\mathrm{MoH}$, Ministry of Health; PV, pharmacovigilance. $p$ values were generated using the: ${ }^{\mathrm{a}}$ Pearson $\chi^{2}$ test and ${ }^{\mathrm{b}}$ Fisher exact test.

${ }^{1}$ Multiple responses were possible. 


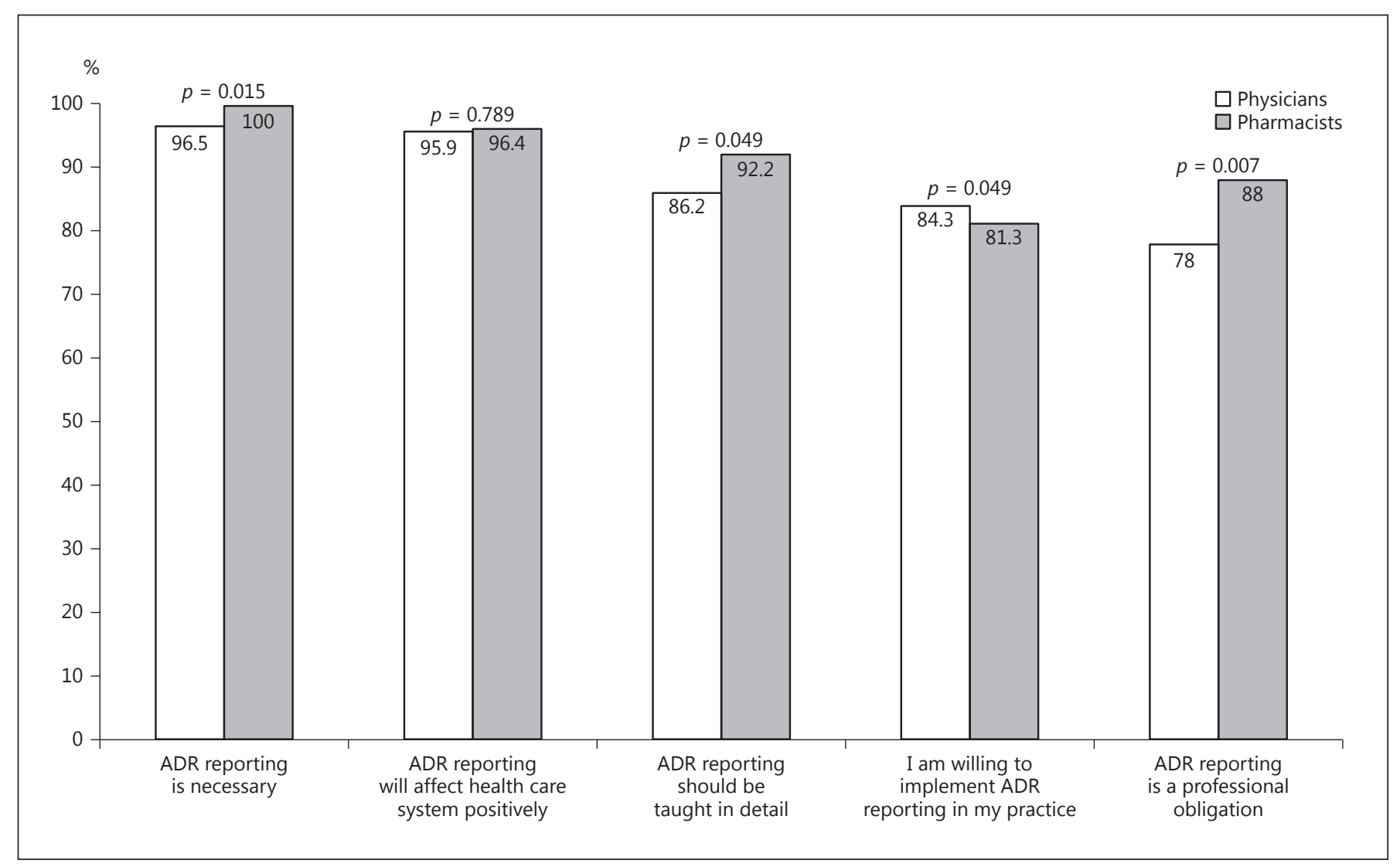

Fig. 1. Attitudes towards reporting of ADR by physicians and pharmacists.

a pilot study was conducted among 14 physicians and 10 pharmacists across 10 polyclinics in 4 different health governorates. Minor formatting changes of the questionnaire layout were made to improve clarity, but without changing the essence of the questions. The pilot study data were excluded from the study results.

\section{Sample Size Calculation and Sampling Strategy}

At the time of conducting this study, information on the number of physicians and pharmacists per polyclinic was not available, so a list of polyclinics was obtained from the $\mathrm{MoH}$; this included 98 polyclinics across the 5 health governorates. A proportional number representing $40 \%$ of polyclinics from every governorate was calculated, and this represented 38 clinics; 11 in Capital, 8 in Farwaniyah, 7 in Ahmadi, 6 in Hawally, and 6 in Jahra were selected for data collection.

Preliminary field work prior to initiating the study showed that there were a total number of 1,200 physicians and 518 pharmacists working in primary care clinics in Kuwait. Using Raosoft online software for sample size calculation [19] which required the total number of participants, it was found that assuming a margin of error of $5 \%$ and a confidence interval of $95 \%$, a minimum sample of 292 physicians and 221 pharmacists was required. To reach the minimum required sample size, a larger number of questionnaires were distributed. Thus, 386 questionnaires were distributed to the physicians. It was not possible to distribute the minimum calculated number of 221 questionnaires to the pharmacists due to the constraints of their working schedules (morning, afternoon, and evening shifts); 197 questionnaires were therefore distributed. A total of 318 and 167 questionnaires were completed and returned by physicians and pharmacists, respectively.

\section{Sample Recruitment, Data Collection Procedures, and Data Analysis}

Physicians and pharmacists from the selected polyclinics were invited to take part in the study. An informed consent form was signed by those who agreed to take part, i.e., 318 physicians and 167 pharmacists. Pharmacy students distributed the questionnaires and followed up weekly during the data collection period to collect the completed questionnaires from the participants.

Data analysis was done using SPSS v23 (2014; IBM Corp., Armonk, NY, USA). Categorical variables were described using numbers and percentages. A normality test was conducted for continuous variables. If data were normally distributed, then mean and standard deviation (SD) were used; if not normally distributed, median and interquartile range (IQR) were used. The Pearson $\chi^{2}$ test or Fisher exact test were used to assess the association between 2 categorical variables wherever appropriate. Quantitative variables were compared between 2 independent groups using the in- 


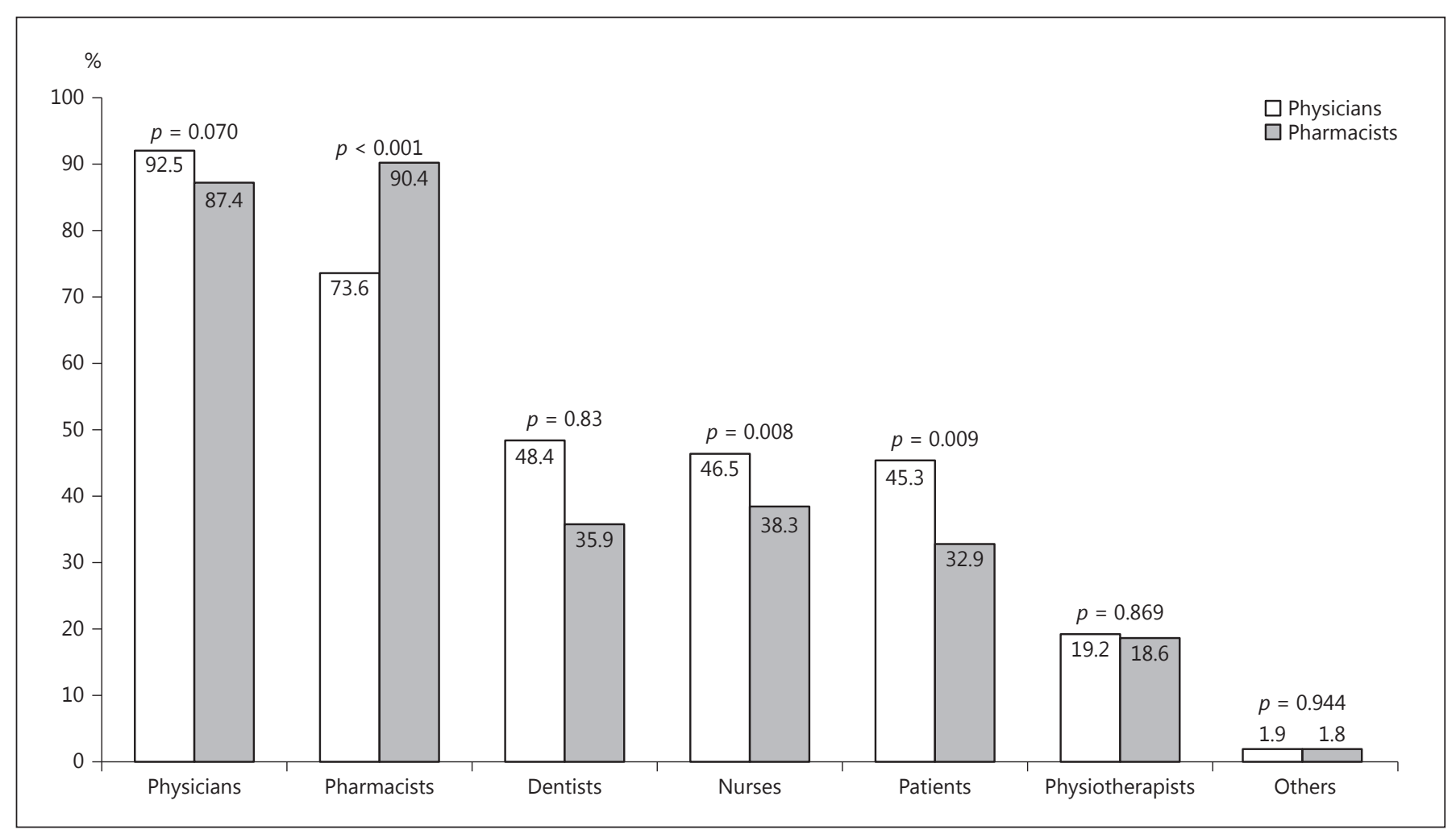

Fig. 2. Physician and pharmacist perceptions of people qualified to report ADR. Multiple responses were possible.

dependent-samples $t$ test or the Mann-Whitney $U$ test depending on the normality of the variables. $p<0.05$ was considered statistically significant. Responses to the open-ended questions were then grouped into relevant issues and presented based on the frequency of reporting.

\section{Results}

\section{Demographics}

A total of 583 questionnaires were distributed (386 to physicians and 197 to pharmacists). Of these, 485 were completed and returned (318 from physicians and 167 from pharmacists), giving an overall response rate of $83.2 \%$.

The study sample consisted of $65.6 \%$ physicians (318/485) and 34.4\% pharmacists (167/485). The sociodemographic characteristics of the participants are presented in Table 1. The majority were non-Kuwaitis (350/485; $73.8 \%$ ). The pharmacists were significantly younger than the physicians $(36.7$ vs. 41.7 years; $p<0.001)$. Significantly more physicians had $>10$ years' experience (214/318 vs. $87 / 167$, i.e., 67.3 vs. $52.1 \%$; $p<0.001$ ).

ADR Reporting in Primary Care Settings in Kuwait

\section{Knowledge about PV and ADR Reporting}

Results showed that more than half of the participants knew the correct definition of PV $(256 / 485 ; 52.8 \%)$ and its purpose $(300 / 485 ; 62.0 \%)$ as well as the correct definition of an ADR (341/485; 70.5\%) (Table 2). Significantly more pharmacists provided the correct answers regarding the PV definition ( $105 / 167$ vs. $151 / 318$, i.e., 62.9 vs. $47.5 \% ; p<0.001)$ and its purpose (123/167 vs. $177 / 318$, i.e., 74.1 vs. $55.7 \%$; $p<0.001$ ).

Participants were presented with 6 options describing types of ADR: (1) all serious ADR, (2) ADR to herbal and nonallopathic drugs, (3) ADR to new drugs, (4) ADR to vaccines, (5) unknown ADR to old drugs, and (6) all of the above. They were instructed to choose 1 option which they believed represented the type of ADR that should be reported. Significantly more physicians selected the correct option regarding which ADR should be reported (254/318 vs. $110 / 167$, i.e., 79.9 vs. $66.3 \%$; $p=$ $0.001)$. Most participants $(434 / 485 ; 89.4 \%)$ were not aware of any ADR reporting center in Kuwait (Table 2). Proportionately more pharmacists thought that ADR should be reported to the KDFC (69/167 vs. $84 / 318$, i.e., 
Table 3. Attitudes and practices of $\mathrm{PV}$ and ADR reporting among physicians and pharmacists working at the polyclinics in Kuwait $(n=485)$

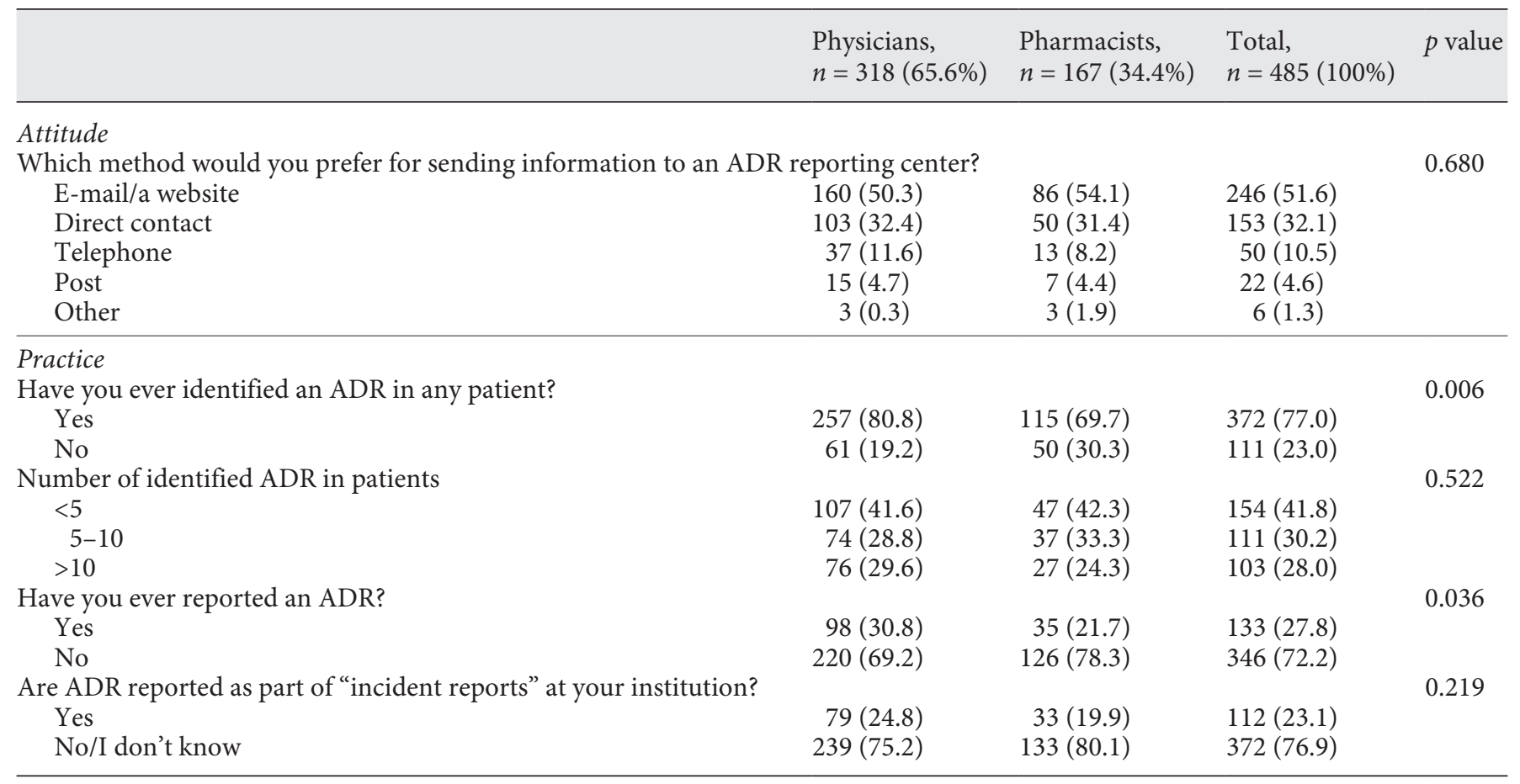

Values are expressed as $n(\%)$ and may not add up due to missing data. PV, pharmacovigilance; ADR, adverse drug reactions. $p$ values were generated using the Pearson $\chi^{2}$ test.

41.3 vs. $26.4 \% ; p<0.001)$, the $\mathrm{MoH}(70 / 167$ vs. $108 / 318$, i.e., 41.9 vs. $34.0 \%$; $p=0.084)$, or pharmaceutical companies ( $40 / 167$ vs. $48 / 318$, i.e., 24.0 vs. $15.1 \%$; $p=0.016$ ). However, more physicians thought they should report ADR to their hospital/clinic ( $104 / 318$ vs. $42 / 167$, i.e., 32.7 vs. $25.1 \%$; $p=0.085)$. Significantly more physicians ( $128 / 318$ vs. $45 / 167$, i.e., 40.3 vs. $26.9 \%$; $p=0.004$ ) stated that they did not know where ADR should be reported (Table 2).

\section{Attitudes about $P V$ and ADR Reporting}

Almost every physician and pharmacist thought that ADR reporting is necessary (307/318 and $167 / 167$, i.e., 96.5 and $100 \%$, respectively), would positively impact the health care system $(305 / 318$ and $161 / 167$, i.e, 95.9 and $96.4 \%$, respectively), and were willing to implement ADR reporting in their daily practice (268/318 and $136 / 167$, i.e., 84.3 and $81.3 \%$, respectively). Statistically more pharmacists believed that PV should be taught in detail to HCP (154/167 vs. $274 / 318$, i.e., 92.2 vs. $86.2 \%$; $p=0.05$ ) and that $\mathrm{ADR}$ reporting is a professional obligation (147/167 vs. $248 / 318$, i.e., 88.0 vs. $78.0 \%$; $p=0.01$ ) (Fig. 1 ).
Physicians were considered to be qualified individuals to report ADR, followed by pharmacists, dentists, nurses, and patients and physiotherapists (Fig. 2). Significantly fewer physicians than pharmacists believed that pharmacists were qualified to report ADR (234/318 vs. 151/167, i.e., 73.6 vs. $90.4 \%$; $p<0.001)$. Significantly more physicians than pharmacists believed that dentists (154/318 vs. $60 / 167$, i.e., 48.4 vs. $35.9 \% ; p=0.01)$ and patients $(144 / 318$ vs. $55 / 167$, i.e., 45.3 vs. $32.9 \%$; $p=0.01$ ) were qualified to report ADR.

The preferred method for reporting ADR was either by e-mail or on-line reporting via a website $(246 / 485 ; 51.6 \%)$, followed by direct contact with a person $(153 / 485 ; 32.1 \%)$ (Table 3). Phone contact or mailing an ADR report were other options selected by participants to a lesser extent. There were no statistical differences when comparing responses given by physicians and pharmacists.

\section{Practices and Barriers to ADR Reporting}

The majority of the participants $(372 / 485 ; 77.0 \%)$ but significantly more physicians had identified an ADR in their practice $(257 / 318$ vs. $115 / 167$, i.e., 80.8 vs. $69.7 \%$; 


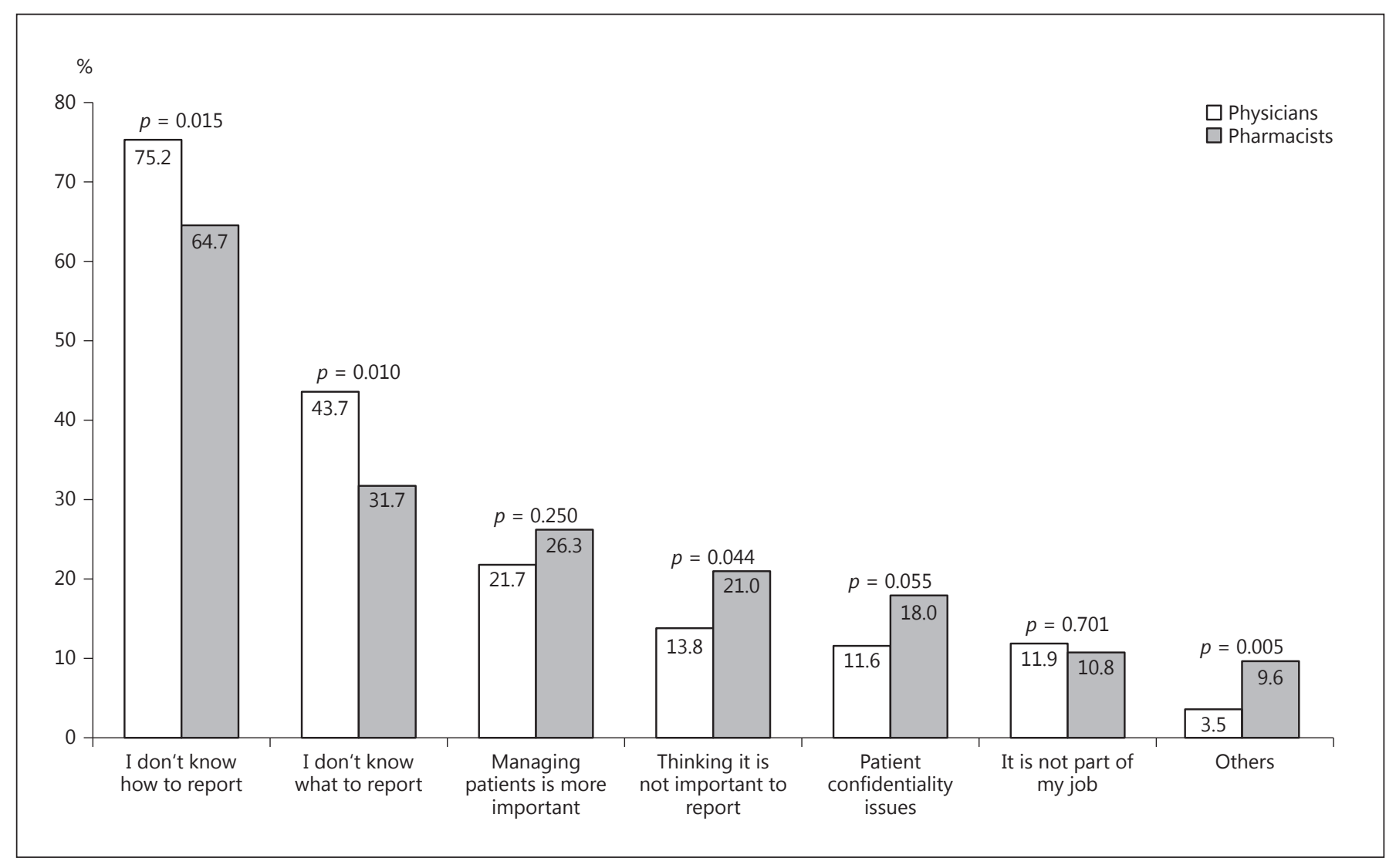

Fig. 3. Barriers for reporting of ADR according to physicians and pharmacists. Multiple responses were possible.

$p=0.006)$ (Table 3$)$. However, only a small proportion of the participants $(133 / 485 ; 27.8 \%)$, significantly more physicians, had ever reported an ADR ( $98 / 318$ vs. $35 / 167$, i.e., 30.8 vs. $21.7 \%$; $p=0.036)$. About one-quarter of the participants $(112 / 485 ; 23.1 \%)$ had reported ADR in the incident reports in the clinic. Reasons preventing participants from reporting ADR are summarized in Figure 3. The 2 most-often cited reasons by physicians and pharmacists were not knowing how to report (239/318 and 108/167, i.e., 75.2 and $64.7 \%$; $p=0.015)$ and what information to report ( $139 / 318$ and $53 / 167$, i.e., 43.7 and $31.7 \% ; p=0.01)$.

About $28 \%(136 / 485)$ of the participants provided responses to the open-ended questions. The barriers most often cited by those who responded were the lack of: knowledge, awareness, education, and training (70/136; $51.5 \%)$; clear guidelines by policy makers, regulators, and health authorities (49/136; 36.0\%); well-trained staff (22; $16.2 \%)$; motivation/time/interest $(31 ; 22.8 \%)$, and financial support and incentives $(16 ; 11.8 \%)$. Suggestions to improve ADR reporting and implement a formal PV center in Kuwait included providing education through reg- ular training sessions/lectures (26/136; 19.1\%), allocating incentives $(16 / 136 ; 11.8 \%)$, and having clear guidelines/ protocols set by the KDFC about how and where to report $\operatorname{ADR}(15 / 136 ; 11.0 \%)$.

\section{Discussion}

In this study, pharmacists had a better knowledge of PV and ADR reporting than physicians, but both were unclear as to where ADR should be reported. Despite a positive attitude, reporting practices were suboptimal; the major barriers to reporting were not knowing how or what to report. Physicians were significantly older and had more years of practice than pharmacists. However, pharmacists reported a better knowledge of PV and ADR than physicians. These observations are comparable to those reported previously in different health care settings in developing countries $[8,10,14,20]$. This difference in knowledge may be associated with the nature of the training for pharmacists, where significant emphasis is placed 
on medicines and their safety [8]. Significantly more physicians than pharmacists knew which type of ADR should be reported (79.9 vs. $66.3 \%$ ), even though fewer of them knew the correct ADR definition (66.7 vs. 77.7\%), similar to previous findings [8]. The discrepancy between knowing how to define an ADR and what constituted a reportable ADR would indicate that the theoretical definition of an ADR did not allow HCP to translate it to the type of ADR that should be reported. However, educational interventions are associated with increased knowledge, identification, and reporting of ADR [21, 22], suggesting that training HCP with real clinical cases might help address this discrepancy.

Most participants (89.4\%) were not aware of any ADR reporting system in Kuwait. Over one-third (35.7\%), and significantly more physicians than pharmacists ( 40.3 vs. $26.9 \%)$, did not know where to report ADR. These findings have been repeatedly documented $[8,10,13,16,20]$. More pharmacists thought ADR should be reported to the regulatory agency (KDFC) or to the $\mathrm{MoH}$, but more physicians thought ADR should be reported within their clinic. Due to the nature of their respective professional tasks, this discrepancy could be due to the fact that pharmacists are more involved in the management of medicines and have a closer link to the particular branch of the $\mathrm{MoH}$ responsible for medicine safety surveillance.

Participants had an overall positive attitude towards ADR reporting, which confirms previous studies from developing countries $[10,14,16,20,23]$. In fact, the results of another study comparing physicians and pharmacists in the primary care setting showed that both have a positive attitude to the fact that reporting ADR is necessary, that it is their professional responsibility, and that it should be taught in detail to HCP [20].

The proportion of participants willing to implement ADR reporting in their practice was lower $(83.2 \%)$ than the response to other aspects of ADR reporting (Fig. 1), suggesting that this might not be perceived as favorable. This suggestion could be due to the observation that, compared to other aspects of ADR reporting, a smaller proportion $(81.4 \%)$ of participants felt that ADR reporting was their professional responsibility. These findings are supported by previous studies conducted in Kuwait among physicians and pharmacists in the public and private hospital sectors $[10,17]$. If HCP did not feel it is their responsibility to report $\mathrm{ADR}$, then they were less willing to modify their practice accordingly and also less likely to report ADR.

Most participants (77\%) had previously identified ADR, but only a small percentage $(27.8 \%)$ had reported them. Significantly more physicians than pharmacists had done so; this could be associated with the direct involvement of physicians with patients and their overall experience in managing ADR. These observations are supported by similar findings from the Middle East $[8,10-12,17,20$, 23], but are in contrast with data from Malaysia showing that more pharmacists than physicians had identified and reported ADR [20]. The authors suggested that these differences might be due to the early introduction of PV training in the undergraduate pharmacy curriculum, which was not the case in the physician curriculum. Furthermore, about one-quarter $(23.1 \%)$ said that ADR were reported as incident reports in their clinic, suggesting that those who reported ADR might have done so using incident reports, believing that this constitutes ADR reporting, instead of reporting to the KDFC.

Similar to previous reports, the 2 main reasons that prevented participants from reporting ADR in our study were not knowing how and what to report. Similar to our results, other barriers previously reported included a lack of: education/training, clear enforceable guidelines by policy makers, regulators, and health authorities, and the time and motivation to report $[10,11,14,23]$. Published data showed that HCP found it difficult, complex, and time-consuming to fill out a standard ADR reporting form [20]. Perhaps ADR reporting would increase by providing practical training to enable HCP to identify ADR, efficiently fill out an ADR report form, and know how to submit this form to the KDFC. Published data shows that interventions to raise awareness and increase knowledge are associated with increased ADR reporting $[21,22]$. HCP who actively report ADR are a positive role model in their working environment [24]. However, a sustained intervention might be needed to ensure an improvement in ADR reporting [21].

Regulators play a crucial role in instituting a National PV Center and ensuring that ADR are being reported; as such, they should provide clear guidelines for reporting. Recently, significant efforts were made in Kuwait to have an official PV unit, allowing Kuwait to become a participating member of the WHO Programme for International Drug Monitoring, similar to countries such as Malaysia, India, Bangladesh, Nepal, Egypt, Jordan, Iran, Iraq, Saudi Arabia, Oman, and the United Arab Emirates [25]. Being a member of this program would enable Kuwait to compare their safety data with that of other countries in the region and worldwide, and also allow independent decision-making regarding product labels, without having to rely on international data that may not be suitable for Kuwait. Compared to other countries in the Gulf re-
Lemay/Alsaleh/Al-Buresli/Al-Mutairi/ Abahussain/Bayoud 
gion (e.g., Saudi Arabia, Oman, and the United Arab Emirates), Kuwait does not have a formal PV unit.

The main limitation of this study was reaching the targeted sample size for pharmacists. In Kuwait's primary health care system, there are approximately twice as many physicians as pharmacists, so the required sample size was approximately 24 and $43 \%$ of the total number of physicians and pharmacists, respectively. The pool of eligible participants being larger for physicians made it easier to reach the projected sample size, but this was not the case for pharmacists. Although the questions used in the study questionnaire were derived from previously pretested tools, the questionnaire was, in fact, not tested for reliability in this specific population. Moreover, some of the questions were dependent on the ability of respon- dents to recall information, such as any ADR identified during their years in practice; this may have led to a response bias [26].

\section{Conclusion}

This study showed that physicians and pharmacists in Kuwait's primary health care setting have adequate knowledge and a positive attitude toward PV and ADR reporting, but suboptimal reporting practices. The major barriers to reporting are not knowing how to report, what information to report, and where this information should be reported. As such, education and training interventions would help improve reporting practices.

\section{References}

1 Starfield B, Shi L, Macinko J: Contribution of primary care to health systems and health. Milbank Q 2005;83:457-502.

2 Health and Vital Statistics Division, National Center of Health: Annual Health Report, Ministry of Health Kuwait, 2013.

3 Accreditation Canada International: Required Organizational Practices Handbook, 2009. https://accreditation.ca/required-organizational-practices-handbook-2017-version-2 (accessed 19 April 2017).

4 Kongkaew C, Noyce PR, Ashcroft DM: Hospital admissions associated with adverse drug reactions: a systematic review of prospective observational studies. Ann Pharmacother 2008;42:1017-1025.

5 WHO: http://www.who.int/medicines/areas/ quality_safety/safety_efficacy/pharmvigi/en/ (accessed 7 December 2017).

6 Wilbur K: Pharmacovigilance in the Middle East: a survey of 13 Arabic-speaking countries. Drug Saf 2013;36:25-30.

7 League of Arab States: Guideline on Good Pharmacovigilance Practice for Arab Countries for Medicinal Products for Human Use, 2014. http://www.jfda.jo/EchoBusV3.0/SystemAssets/PDF/AR/PharmVigilance/TheGoodPharmacovigilancePracticev2.pdf (accessed 19 April 2017).

-8 Dorji C, Tragulpiankit P, Riewpaiboon A, et al: Knowledge of adverse drug reaction reporting among healthcare professionals in Bhutan: a cross-sectional survey. Drug Saf 2016;39:1239-1250.

-9 González-Rubio F, Calderón-Larrañaga A, Poblador-Plou B, et al: Underreporting of recognized adverse drug reactions by primary care physicians: an exploratory study. Pharmacoepidemiol Drug Saf 2011;20:1287-1294.
10 Alsaleh FM, Alzaid SW, Abahussain EA, et al: Knowledge, attitude and practices of pharmacovigilance and adverse drug reaction reporting among pharmacists working in secondary and tertiary governmental hospitals in $\mathrm{Ku}$ wait. Saudi Pharm J 2017;25:830-837.

11 Jose J, Jimmy B, Al-Ghailani AS, et al: A crosssectional pilot study on assessing the knowledge, attitude and behavior of community pharmacists to adverse drug reaction-related aspects in the Sultanate of Oman. Saudi Pharm J 2014;22:163-169.

12 Wilbur K: Pharmacovigilance in Qatar: a survey of pharmacists. East Mediterr Health J 2013;19:930-935.

13 Vessal G, Mardani Z, Mollai M: Knowledge, attitudes, and perceptions of pharmacists to adverse drug reaction reporting in Iran. Pharm World Sci 2009;31:183-187.

14 Alshammari TM, Alamri KK, Ghawa YA, et al: Knowledge and attitude of health-care professionals in hospitals towards pharmacovigilance in Saudi Arabia. Int J Clin Pharm J 2015; 37:1104-1110.

15 Khan T: Community pharmacists' knowledge and perceptions about adverse drug reactions and barriers towards their reporting in Eastern Region, Alahsa, Saudi Arabia. Therap Adv Drug Saf 2013;4:45-51.

16 Suyagh M, Farah D, Abu Farha R: Pharmacist's knowledge, practice and attitudes toward pharmacovigilance and adverse drug reactions reporting process. Saudi Pharm J 2015;23:147-153.

17 Alsaleh, FM, Lemay, J, Al Dhafeeri RR, et al: Adverse drug reaction reporting among physicians working in private and government hospitals in Kuwait. Saudi Pharm J 2017;25: 1184-1193.
18 Khan MU, Ahmad A, Ejaz A, et al: Comparison of the knowledge, attitudes, and perception of barriers regarding adverse drug reaction reporting between pharmacy and medical students in Pakistan. J Educ Eval Health Prof 2015;12:1-6.

19 Raosoft I: Sample Size Calculator, 2004. http://www.raosoft.com/samplesize.htm.

20 Tew MM, Teoh BC, Mohd Baidi AS, et al: Assessment of knowledge, attitude and practices of adverse drug reaction reporting among doctors and pharmacists in primary healthcare. Adv Pharmacoepidemiol Drug Saf 2016; 5:206.

21 Biagi C, Montanaro N, Buccellato E, et al: Underreporting in pharmacovigilance: an intervention for Italian GPs (Emilia-Romagna region). Eur J Clin Pharmacol 2013;69:237-244.

22 Figueiras A, Herdeiro MT, Polonia J, et al: An educational intervention to improve physician reporting of adverse drug reactions: a cluster-randomized controlled trial. JAMA 2006;296:1086-1093.

23 Wilbur K: Pharmacovigilance in Qatar: a pharmacist survey. Value Health 2012; 15:A292.

24 Passier A, ten Napel M, van Grootheest K, et al: Reporting of adverse drug reactions by general practitioners: a questionnaire-based study in the Netherlands. Drug Saf 2009;32: 851-858.

25 World Health Organization: Members of the WHO Programme for International Drug Monitoring, 2017. https://www.who-umc. org/global-pharmacovigilance/members/ who-programme-members/ (accessed 23 April 2017).

26 Smith F: Conducting Your Pharmacy Practice Research Project - A Step-by-Step Guide. London, Pharmaceutical Press, 2006. 